1911 - «Ferreira da Silva funda a Sociedade de Química Portuguesa, à qual sucedeu mais tarde a Sociedade Portuguesa de Química e Física.» (1)

1917 - «Alberto de Aguiar, ilustre químico discípulo de Ferreira da Silva, passou a reger Química Biológica.» (2)

1924 - «Branca Edmée Marques foi nomeada assistente de Química da Faculdade de Ciências da Universidade de Lisboa. Mais tarde passou a primeiro assistente da mesma faculdade.» (3)
1925 - O professor Alberto de Aguiar publica uma valiosa manografia intitulada "A Quimica no Porto» onde a traceja com larga documentação e certo espírito crítico. (2)

1926 - Funda-se a Sociedade Portuguesa de Quimica e Física. $(1,2)$

1939 - Branca Edmée Marques funda o laboratório de Radioquímica da Faculdade de Ciências de Lisboa. (3)

\title{
LIVROS... LIVROS... LIVROS... LIVROS...
}

\section{ADVANCED WASTE TREATMENT OF LIQUID EFFLUENTS, PUBLICATION SERIES N. ${ }^{\circ} 6$, SOCIETY OF CHEMICAL INDUSTRY, LONDON, 1979 , \\ EUROPEAN FEDERATION OF CHEMICAL ENGINEERING (EFCE). (*)}

Idioma: inglês

N. ${ }^{\circ}$ de páginas: 140

ISBN 0901001635

Esta monografia é o resultado do relatório de um Grupo de Trabalho estabelecido pela Comissão de Aspectos Ambientais da Engenharia Química da Federação Europeia de Engenharia Quimica. O relatório apresenta cinco capítulos de autores diferentes precedidos de um capítulo introdutório redigido pelo Presidente do Grupo de Trabalho. A má revisão bibliográfica bem como a inexistência de um indice de matérias, para já não falar de índice remissivo, levam a crer não ter havido editor.

Como é corrente neste tipo de publicação, os capitulos são de qualidade desigual pelo que nesta rubrica se tentará dar uma ideia da importância de cada capitulo. Assim, o capítulo introdutório, da autoria de D. Anderson, define tratamento avançado, tal como entendido no âmbito desta monografia, como a tecnologia que compreende «os processos químicos, físico-químicos, biofísicos e biológicos normalmente não incluídos nas estações de tratamento clássicas» e apresenta sob forma tabular uma boa comparação entre as eficiências de remoção de vários produtos nas diferentes operaçōes consideradas como cabendo nesta definição de tratamento avançado. Este capitulo descreve ainda, de forma sumária, alguns dos processos e operações consideradas na monografia, sob os títulos a) tratamento físico-químico, b) filtração, c) remoção de nutrientes e d) adsorção, não referindo os processos de separação por membrana, tratados no capítulo IV e incluindo filtração, que não é abordada neste relatório, mas é utilizada em muitos dos sistemas avançados de tratamento, quer precedendo este quer no próprio sistema de tratamento. As figuras referidas no texto, apresentadas no fim do capitulo, são bastante elucidativas - pena é que a ausência de título e numeração que as relacione com o texto torne mais árduo o trabalho do leitor.

O capítulo II, tratamento físico-químico de efluentes líquidos, da autoria de J. Bechaux é relativamente pobre limitando-se a descrever brevemente a utilização de processos de precipitação, já que os processos de adsorção, separação por membranas e remoção por ar (air stripping) são abordados noutros capitulos e porque não abordam os processos de destilação ou extração por solvente. A autora refere brevemente as formas de utilização isolada ou conjunta dos sais mais usados como coagulantes - floculantes (sulfatos de alumínio, sais de ferro(III) e cal) com breve referência aos polielectrólitos utilizados como adjuvantes de floculação; as dificuldades de operação que alguns destes processos apresentam não são escamoteadas. São também claramente identificadas as diferenças entre sistemas de precipitação directa (isto é, em que não há qualquer tratamento biológico) e conjunta com tratamento biológico quer se trate de pré precipitação simultânea ou pós precipitação; sobretudo nas conclusões, a aplicabilidade de cada um destes sistemas às diferentes solicitações a exigir (sobrecargas temporárias em estâncias de férias, remoção de substâncias tóxicas, remoção de fósforo, tratamento parcial de efluentes,...) é pedagogicamente descrita. À parte isso, o capítulo limita-se a referir o número e tipo de instalações existentes nas várias partes do mundo, dando algumas indicações das percentagens de remoção de alguns dos poluentes mas não apresentando qualquer comparação ou indicação de valor absoluto dos custos de instalação e operação.

A utilização de adsorção por carvão activado é revisto no capítulo III, da autoria de H. J. Kämpf. Começando por referir as vantagens do uso do carvão activado - residuais absolutos de produtos orgânicos muito baixos, ausência de poluição líquida posterior quando se procede a regeneração do carvão activado, capacidade de «encaixar» variação de carga poluidora, flexibilidade de operação permitindo variação da qualidade do efluente - o autor revê brevemente a teoria da adsorção, referindo-se aos vários factores que a influenciam, descreve as formas de produtos e propriedades dos tipos granular e pulverento,deixando clara a necessidade de proceder à realização de testes em escala reduzida para predizer o rendimento e forma de utilização do carvão activado para o tratamento de cada efluente concreto. A descrição processual, compreendendo o pré tratamento, é sucinta, concisa e quase completa, o mesmo acontecendo no que se refere ao projecto do equipamento - as indicações aqui contidas

(*) Os livros apresentados nesta rubrica podem ser consultados na Biblioteca da S.P.Q., Av, da República, 37, 4. ${ }^{\circ}, 1000$ Lisboa. 
são bastante práticas, encontrando-se normalmente ausentes em obras de maior fôlego. Os dois últimos subtítulos abordam a regeneração e reactivação do carvão activado, válida para instalações de grande porte e uma descriminação boa de parâmetros de custo de investimentos e operações.

O Dr. G. V. R. Mattock apresenta, no capitulo IV, um trabalho cuidadosamente elaborado, com um bom número de figuras permitindo visualizar melhor os diferentes tipos de membranas utilizadas em tratamento de efluentes, nomeadamente osmose inversa, ultrafiltração e electro diálise. Os aspectos teóricos são revistos brevemente, bem como as características dos diferentes tipos de membrana. Na discussão sobre significado dos processos de membrana no tratamento de efluentes liquidos o autor deixa claro que a reutilização da água por estes processos é raramente económica, pelo que estes processos têm interesse apenas quando «...o concentrado tem valor... ou quando a água é tão cara ou não pode ser lançada como efluente, devendo ser contempladas formas de recirculação em circuito fechado.» Após uma curta mas detalhada discussão sobre o projecto dos processos de membranas e uma comparação económica cuidada o autor completa o capítulo revendo brevemente a aplicação destas técnicas em vários tipos de indústrias: acabamento metálico (surface treatment), papel e pasta, alimentar, têxtil, farmacêutica e como tratamento terciário de efluentes para reutilização da água.

Os dois últimos capítulos, ambos da autoria do Prof. A. Van Haute, coadjuvado por J. Hermans no quinto e por P. Stolwijk no sexto capítulo, referem-se à remoção de compostos de azoto de efluentes líquidos, por processos biológicos e por processos físico-químicos, respectivamente no quinto e sexto capítulos. Após referir as razões que presidem à necessidade de remoção de azoto dos efluentes (deplecção de oxigénio, eutrofização e nocividade para os peixes em águas de superfície, necessidade de baixos teores de amónia e nitratos em águas a considerar potáveis) os autores revêem os aspectos teóricos clássicos, estequeométricos, cinéticos e microbiológicos, dos processos de nitrificação e desnitrificação relacionando-os com os aspectos práticos de projecto e operação que se vêm tornando correntes.

No sexto e último capítulos são revistos os métodos de permuta iónica, clorinação ao «breakpoint», clorinação-desclorinação e «air stripping» tal como aplicados para a remoção de amónio. Para cada um desses casos são referidos os princípios de base, tipos de utilização e custos de operação. Mencionam-se assim as vantagens e inconvenientes da permuta por resinas orgânicas ou zeólitos inorgânicos, sobretudo clinoptilolite, a estequeometria e cinética das reacções de oxidação por cloro e a necessidade de deschorinar com dióxido de enxofre e a transferência da amónia para o ar conseguida por «Stripping». Conquanto os valores de custo de operação sejam indicados, não parece que os autores tenham tornado suficientemente claro tratar-se de métodos de último recurso, extremamente caros e difíceis de operar e, por vezes, ineficazes se considerados de uma forma global - é o caso, por exemplo, da remoção da amónia para o ar; por dissolução na água atmosférica e posterior precipitação, o azoto assim removido volta à terra, por vezes na mesma bacia hidrográfica da qual se procurou removê-la (caso da estação de tratamento de Lake Tahoe, citada no texto)

Sentindo o envelhecimento do texto - a maior parte dos capítulos não cita qualquer artigo posterior a 1975 - D. Anderson conclui a monografia com cerca de dezassete páginas de bibliografia algo mais actualizada, ainda que pareça descabida a menção de obras básicas, como R. E. Treybel «Mass Transfer Operations» ou P. A. Vesilind «Treatment and Disposal of Wastewater Sludges» ou ainda A. M. P. Skelland «Non-Newtonian Flow and Heat Transfer».

Considerada como obra de divulgação e sistematização de assuntos geralmente dispersos em centenas de artigos soltos, destinada sobretudo aos engenheiros não especializados em tratamento, esta monografia sobrevive às críticas feitas e deve ter um papel de referência em muitas bibliotecas.

\section{ACTIVIDADES DA S.P.Q. Simpósio de Química Orgânica dedicado ao Professor Doutor António Jorge de Andrade Gouveia}

\section{DE NOVEMBRO DE 1981}

Faculdade de Ciências e Tecnologia da Universidade de Coimbra

Departamento de Química

\section{Programa:}

9.30 - Sessão de abertura

10.00 - Lição por professor convidado

11.00 - Café

11.20-11.50 - Comunicações

12.00 - Almoço

14.15-15.15 - Comunicações

15.15 - Café
15.45-17.00 - Comunicações

17.30 - Sessão de encerramento

20.00 - Jantar de Confraternização

Para informações complementares contactar:

Prof. A. Rocha Gonçalves

Departamento de Química

Faculdade de Ciências e Tecnologia

Universidade de Coimbra

3000 COIMBRA

Telefones: 22826

24207 